\title{
Seasonal variation of solitary wave properties in Lake Constance
}

\author{
M. Preusse, ${ }^{1,2}$ H. Freistühler, ${ }^{2}$ and F. Peeters ${ }^{1}$ \\ Received 22 June 2011; revised 21 February 2012; accepted 22 February 2012; published 14 April 2012.
}

[1] The properties of internal solitary waves (ISWs) depend on the stratification of the water body. In most climatic regions the stratification in lakes and oceans varies during the year, and hence the properties of the ISWs can also be expected to change over the seasons. On the basis of a long-term temperature time series recorded over 6 years, this paper investigates seasonal changes in the characteristic properties of ISWs in Lake Überlingen, a subbasin of Lake Constance. A large number of ISWs with amplitudes ranging from $3 \mathrm{~m}$ to $30 \mathrm{~m}$ were identified. More than $15 \%$ of the leading ISWs of a wave train were associated with density inversions, often indicating shear instabilities or trapped cores. For all waves the propagation depth and the value of a nonlinearity index $n l_{p}$ providing the degree of nonlinearity were determined, propagation depth being the rest height of the isotherm undergoing maximum displacement and $n l_{p}$ the ratio between wave amplitude and propagation depth. The index $n l_{p}$ was found to be a good parameter for predicting the occurrence of inversions. The statistical analysis of the wave properties derived from the observations revealed that the degree of nonlinearity of the ISWs changes with season. Complementary to the statistical analysis, the seasonally averaged ISW properties were compared with wave prototypes obtained numerically from the Dubreil-Jacotin-Long (DJL) and the stratified Korteweg-deVries (KdV) models. The simulations indicate that the typical stratification and its seasonal variation are responsible for the degree and the seasonality of nonlinearity of the ISWs.

Citation: Preusse, M., H. Freistühler, and F. Peeters (2012), Seasonal variation of solitary wave properties in Lake Constance, J. Geophys. Res., 117, C04026, doi:10.1029/2011JC007403.

\section{Introduction}

[2] Internal solitary waves (ISWs) are ubiquitous in the ocean [Helfrich and Melville, 2006; Jackson, 2007] and are also frequently observed in lakes [Horn et al., 2001]. Their wide occurrence has led to investigations of their influence on aquatic ecosystems [Boegman and Ivey, 2009; Huber et al., 2011; Lorke, 2007; Stastna and Lamb, 2008]. An outstanding property of these waves is the long-lasting stability of their shape [Miles, 1980]. This led to the conception that ISWs propagate undisturbed through a lake until they break at the boundaries [Boegman et al., 2005]. As zones of internal solitary wave-breaking and subsequent mixing, coastal or littoral regions received special attention. Several studies have confirmed the important role of boundary mixing for the overall vertical transport of dissolved substances in lakes and oceans [Goudsmit et al., 1997; Ledwell et al., 1993]. The breaking of ISWs contributes to the enhanced turbulence observed in the boundary regions and is therefore a driver of mixing in the thermocline [Lorke, 2007]. There are indications that shoaling ISWs

\footnotetext{
${ }^{1}$ Limnological Institute, University of Konstanz, Konstanz, Germany.

${ }^{2}$ Department of Mathematics and Statistics, University of Konstanz, Konstanz, Germany.

Copyright 2012 by the American Geophysical Union. 0148-0227/12/2011JC007403
}

resuspend sediment from the seabed [Bonnin et al., 2006]. The potential of ISWs for resuspension was also demonstrated in numerical and laboratory experiments [Boegman and Ivey, 2009; Carr et al., 2010; Stastna and Lamb, 2008]. Density overturns generated by ISWs were observed in the pelagic thermocline [Moum et al., 2003; Preusse et al., 2010], suggesting that ISWs also contribute to energy fluxes and mixing in the open water and thus can enhance the vertical fluxes of nutrients that may induce primary production and hence cause plankton patchiness.

[3] The analysis of properties, occurrence, and ecological impact of ISWs in lakes is mostly based on a very limited number of observations because the measuring intervals usually do not exceed one season. Moreover, according to MacIntyre et al. [2009], most studies investigating highfrequency internal waves in lakes were conducted during periods when stratification resembled very closely a twolayer system. Observations can be generalized and intensively analyzed by numerical and laboratory experiments. While this partly explains how parameter values influence ISW properties, the characteristic properties and ecological relevance of ISWs in lakes have remained relatively unclear. In particular, it is the number of occurrences of large or breaking ISWs that determines how much these waves might contribute to e.g., boundary mixing [Lorke, 2007], resuspension [Boegman and Ivey, 2009], particle transport [Pineda, 1999], and plankton distribution [Cuypers et al., 
2011]. Occurrence and characteristics of ISWs could differ substantially over the year due to varying stratification or wind-forcing, implying that the ecological impact of ISWs likely changes significantly with season. The theory of ISWs predicts how the wave properties change with stratification and amplitude [Benney, 1966; James, 1997]. From a modeling perspective, the degree of nonlinearity is one of the most crucial ISW properties, since it determines the applicability of models for weakly nonlinear waves [Grue et al., 1999; Vlasenko et al., 2000].

[4] Individual ISWs can be mathematically modeled by the Dubreil-Jacotin-Long (DJL) equation, which governs the stream function of any traveling-wave solution of the Euler equations for heterogeneous incompressible fluids [Dubreil-Jacotin, 1935; Long, 1956; Stastna and Lamb, 2002; Turkington et al., 1991]. While the DJL is fully nonlinear and valid to the (presumably very high) degree to which the Euler equations hold, qualitative reasoning, approximation arguments [Benney and Ko, 1978], and experience [Grue et al., 1999; Ostrovsky and Stepanyants, 2005] have indicated that significant information may often be obtained from the much simpler stratified Korteweg-deVries (KdV) model which assumes a factorization of the wave shape in a vertical dependence and a weakly nonlinear horizontaltemporal dependence [Benjamin, 1967; Benney, 1966]. Detailed knowledge of the degree of nonlinearity of ISWs occurring in the field is essential to decide whether modeling approaches relying on weakly nonlinear theory, such as the Benjamin-Ono equation, the Korteweg-deVries equation, or the Gardener equation [Ostrovsky and Stepanyants, 2005, and references therein], can be applied to simulate the essential features of ISWs occurring in lakes.

[5] ISWs occur frequently in Lake Constance, Germany [Lorke et al., 2006], typically in sequential groups called wave trains. They are known to be generated during the steepening process of an internal basin-scale seiche into an internal surge, which is reflected at the western end of the lake [Appt et al., 2004]. In a previous study it was shown that the passage of ISWs in Lake Constance can be accompanied by turbulence in the pelagic thermocline [Preusse et al., 2010]. Since that study was restricted to 2 weeks during the summer of 2008, the ecological relevance remained open due to the unknown number of occurrences of highly nonlinear ISWs per month, as is often the case with short-term field studies.

[6] Here, we generalize the detailed analyses of shearinduced breaking ISWs by Preusse et al. [2010] in the deep littoral zone of Lake Überlingen, by investigating a total of over 200 wave trains which are led by an ISW of at least moderate amplitude ( $\geq 3 \mathrm{~m}$ ) and were observed over 6 years at the deepest location of Lake Überlingen. The statistical analysis is focused on the degree of nonlinearity of ISWs and its dependence on season as well as on ISW breaking in deep water, all of which relate directly to the ecological relevance of ISWs in lakes. By investigating the nonlinearity parameters of ISWs measured in the field and their correlation with wave-breaking in stratifications that naturally occur in deep lakes in the temperate zone, we generalize some of the laboratory findings of Grue et al. [1999, 2000] that are valid for stratifications untypical for such lakes. Seasonal prototypes of the measured waves are simulated using both the DJL and the stratified KdV model. The purpose of the simulations is not to resolve individual, strongly nonlinear waves with their complicated internal structure but to demonstrate the influence of seasonally varying stratification on the degree of nonlinearity. Complementary to Vlasenko et al. [2000], who used three idealized stratifications corresponding to midlatitude continental shelves, we base our simulations on measured seasonal stratifications that seem typical for sufficiently large lakes in the temperate zone.

\section{Methods}

[7] Subsection 2.1 provides an overview of the experiment while subsection 2.2 explains the methods used to extract the wave properties from the data for the statistical analysis. The numerical models are presented in subsection 2.3 together with their initial conditions.

\subsection{Experiment}

[8] Field data were collected in Lake Überlingen (Figure 1b), a subbasin of Lake Constance (63 km long, $14 \mathrm{~km}$ wide, mean depth $100 \mathrm{~m}$; Figure 1a) in Germany. Lake Überlingen has a maximum depth of $140 \mathrm{~m}$ and a depth of $80 \mathrm{~m}$ at the Sill of Mainau where it joins the main basin. A thermistor chain was deployed in the center of Lake Überlingen at a water depth of $140 \mathrm{~m}\left(47^{\circ} 45^{\prime} 47^{\prime \prime} \mathrm{N}, 09^{\circ} 07^{\prime} 54^{\prime \prime} \mathrm{E}\right)$. The data were collected every minute over the years 2004 2007 and 2009-2010 using a PME thermistor chain with an accuracy of $0.01^{\circ} \mathrm{C}$ or alternatively RBR thermistors with an accuracy of $0.002^{\circ} \mathrm{C}$. The vertical resolution ranged from $10 \mathrm{~m}$ between $50 \mathrm{~m}$ and $130 \mathrm{~m}$ depth, $5 \mathrm{~m}$ between $20 \mathrm{~m}$ and $50 \mathrm{~m}$ depth to a resolution of $2 \mathrm{~m}$ and finer in the upper $20 \mathrm{~m}$. During 2009 the temperature was recorded only between $0.5 \mathrm{~m}$ and $30 \mathrm{~m}$. Lake Constance is a freshwater lake in which salinity gradients have no significant effect on the density gradient. Thus a single vertically resolved temperature time series provides information on the stratification, i.e., the vertical distribution of density, and simultaneously on the one-dimensional properties of ISWs: amplitude, period, propagation depth, and nonlinearity.

[9] Wind speed and direction (Figure 1c) were measured over the years 2004-2009 at a land-based meteorological station at the City of Constance (Figure 1a), approximately $1.5 \mathrm{~km}$ from the lake, by the German Meteorological Service (DWD), and were provided as 10 min mean values. Zenger et al. [1990] demonstrated that the wind field measured at the DWD station correlates well with the wind field in the center of Lake Überlingen.

\subsection{Analysis of ISWs}

\subsubsection{Identification of ISWs (Fitting Procedure)}

[10] The temperature data covering 6 years were statistically processed using an automatic detection of the ISWs and identification of their properties. The success of the automatic detection of ISWs was confirmed by visual inspection of selected sequences of the time series data (Figure 2a). The routine was designed to exclude small $(<3 \mathrm{~m})$ high-frequency waves dominating the background stratification, small trailing waves following the relatively large, clearly defined ISWs of a wave train or malformed waves where the typical wave properties are undefined (white and red arrows in Figure 2a). 

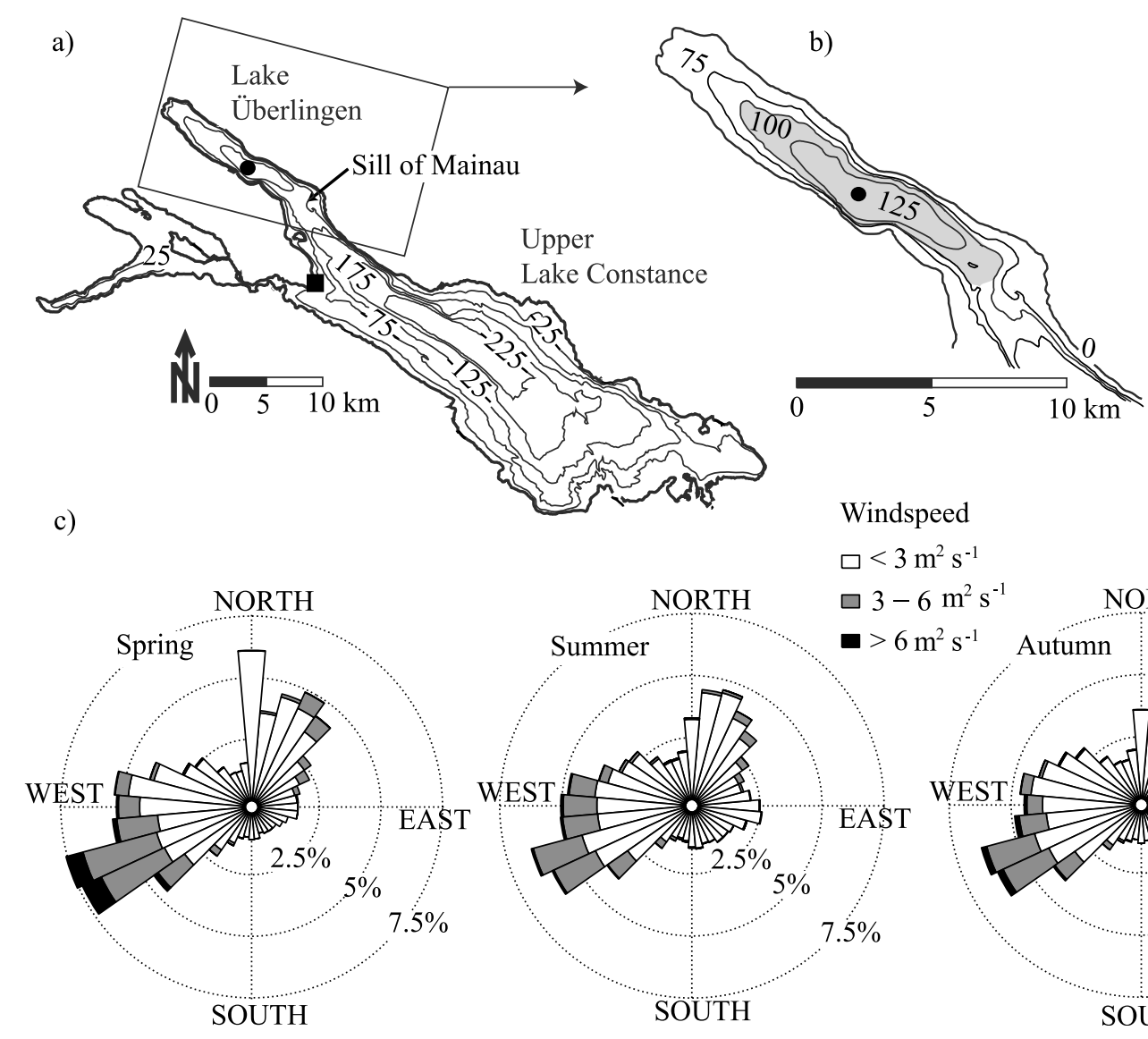

Windspeed

Figure 1. (a) Lake Constance $\left(47^{\circ} 83^{\prime} 99^{\prime \prime} \mathrm{N}, 9^{\circ} 81^{\prime} 89^{\prime \prime} \mathrm{E}\right)$ bathymetry [Wessels, 1998] with the location of the study site (black dot) and wind station (black square). (b) Detailed view of Lake Überlingen. Mean depth of gray region is $125 \mathrm{~m}$. (c) Distribution of wind vectors during spring, summer and autumn (2004-2009).

[11] The automatic procedure was based on time series of isotherm depths that were filtered to identify time intervals during which high-frequency isotherm displacements with a minimal amplitude of $2.5 \mathrm{~m}$ occurred. Afterward, we applied a fitting procedure to the identified time segments that provided the properties of ISWs for later statistical analysis. In the following we explain the procedure step by step.

[12] Time series of isotherm depth, representing temperatures between $4^{\circ} \mathrm{C}$ and $20^{\circ} \mathrm{C}$ in steps of $0.1^{\circ} \mathrm{C}$, were determined from the time series of temperature profiles. Each temperature profile was first sorted to get a monotonic decrease of temperature with depth, thereby removing overturns in the water column. The depth of an isotherm in each profile was then obtained by linear interpolation of temperature versus depth. The time series of isothermal depths were band-pass filtered (Butterworth filter), providing passbands for periods between $2 \mathrm{~min}$ and $30 \mathrm{~min}$. The typical periods of ISWs in Lake Constance measured between July and November 2004 are close to the buoyancy period, i.e., between 3 and 14 min [Lorke et al., 2006]; hence these passbands are rather generous. Isotherms inside the range of minimum and maximum temperature in the water column are called "realized isotherms." All times at which the amplitude of $30 \%$ of the band-pass-filtered realized isotherm depths exceeded $2.5 \mathrm{~m}$ were recorded as "promising" (to be associated with an ISW). The monthly median bandwidth covered by the $30 \%$ of the isotherms with the largest displacements was almost independent of season and year and covered between $5 \%$ and $10 \%$ of the water column. Only in this region were filtered isotherms required to exceed the critical amplitude in order to denote a time as "promising."

[13] Successive promising time steps were combined to a preliminary interval associated with the possible passage of a single ISW. In each preliminary interval the maximum of the filtered isotherm with maximal displacement was evaluated. The times corresponding to the maxima were stored as centers of final intervals of 16 min duration.

[14] We then switched to the original isotherms and calculated the isothermal displacements relative to the isothermal depths at the beginning of each interval. Motivated by ISW theory, we identified ISWs by fitting the empirical function

$$
\eta_{D A T A}(z, t)=a(z) \operatorname{sech}^{2}\left(f(z)\left(t_{0}-t\right)\right)
$$

within the selected $16 \mathrm{~min}$ time intervals to the isothermal displacements (Figures 2e-2f), where $t$ is time and $z$ is the isothermal depth at the beginning of the corresponding interval. The fit was optimized for the ISW properties 

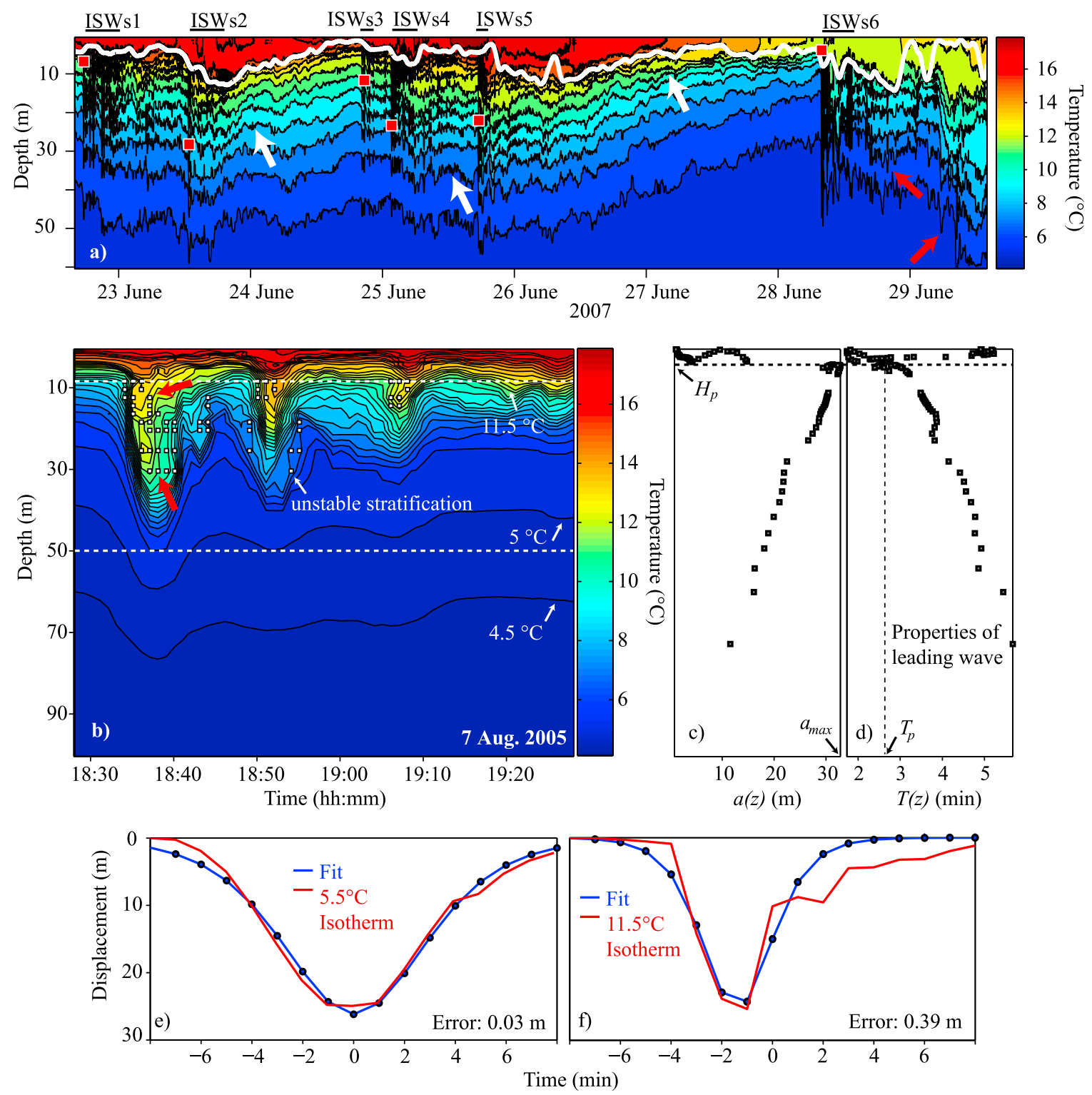

Figure 2. Estimation of internal solitary wave (ISW) properties. (a) Isotherms at $1^{\circ} \mathrm{C}$ intervals showing internal surges accompanied by ISWs. The leading ISWs of the wave trains marked by red squares were found by the algorithm, the wave corresponding to the first arrow was excluded by the fitting routine, and the wave corresponding to the second arrow was excluded by the amplitude criterion. The depths of the red squares represent the propagation depths of the ISWs, the white line shows the low-pass-filtered thermocline depth (Butterworth, cutoff frequency $1 \mathrm{~h}$ ), and the white arrows point to randomly chosen highfrequency waves. (b) Isotherms in $0.5^{\circ} \mathrm{C}$ distance showing a large-amplitude ISW train. Squares indicate overturns. Red arrows mark the first and last inversion used to calculate the vertical instability range. Vertical profile of the (c) $a(z)$ measured at the leading wave center and (d) leading wave $T(z)$. (e, f) Examples of single fits corresponding to the leading ISW.

frequency $f(z)$, time $t_{0}$ of passage of the wave trough and displacement amplitude $a(z)$. Note that this function is more general than the fitting function used by Moum et al. [2007] because it allows a frequency $f$ varying with depth, as is typical for large ISWs. In order to exclude badly estimated ISW properties from our analyses, isothermal fits were only considered in the statistics if the fit error was less than $0.2 \mathrm{~m}$, where we define the fit error as mean squared deviation between data and best fit, normed by $a(z)$. We thereby allow a squared mean deviation of $20 \%$ between fit and observation. This criterion excluded waves or some isotherms of waves with a shape deviating from the $\operatorname{sech}^{2}$ function (Figure $2 \mathrm{f}$ and missing values in Figure $2 \mathrm{c}$ ). In total, about $35 \%$ of the promising time intervals were thus discarded in fitting, mostly relatively small, deformed waves following the clearly defined leading waves of a wave train. Ten waves out of 68 large waves with a maximum displacement of at least $10 \mathrm{~m}$ were also excluded. All of these ISWs were 


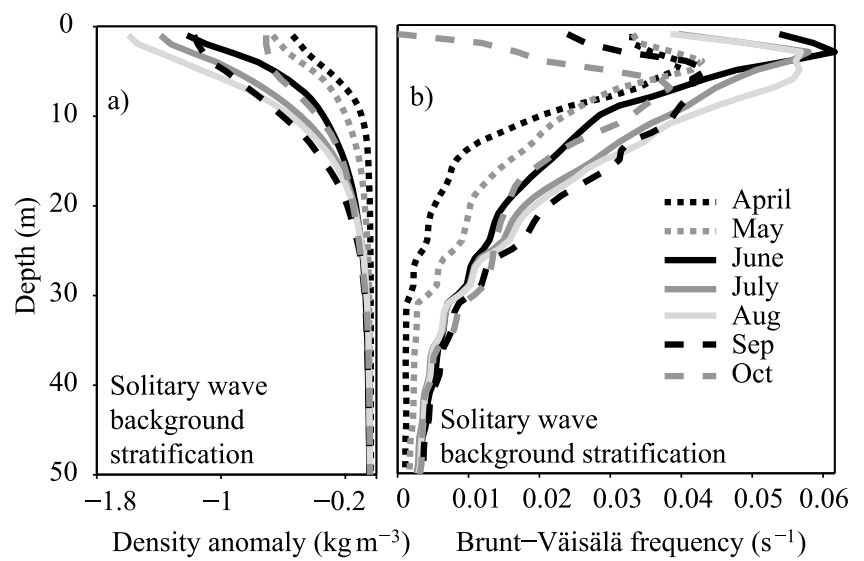

Figure 3. Vertical profiles of (a) ISW density anomalies, corresponding to ISW background temperature profiles averaged over 1 month, used for numerical simulations, and (b) corresponding ISW Brunt-Väisälä frequencies.

breaking, showing that the fitting is sensitive to breaking. However, a large number of breaking ISWs still passed the fitting procedure and were included in the statistical analysis.

[15] Two ISWs were assumed to belong to the same wave train if no more than $3 \mathrm{~h}$ elapsed between their passages. Although this time interval is rather generous (the period between passing waves in a train was usually smaller), it was small enough to allow clear distinctions between different trains. This is due to the relatively long time span of typically more than $9 \mathrm{~h}$ between the passage of internal fronts; while the basin-scale seiche period is between 3 and 5 days, reflected fronts return no sooner than after $9 \mathrm{~h}$.

2.2.2. Estimation of Observed Solitary Wave Properties

[16] Only the properties of the leading ISW in a wave train were analyzed because this wave has the highest probability of having stationary properties, i.e., of being stationary when using a reference frame moving with the wave. We refer to the depth $z$ with $a(z)=\max (a)$ as propagation depth, $H_{p}$, of the ISW (Figure 2c), to the period $T_{p}=1 / f\left(H_{p}\right)$ as wave period (Figure 2d) and to the maximum of the amplitudes of the isothermal displacements $\max (a)=a_{\max }$ as amplitude (Figure 2c).

[17] The degree of nonlinearity, here termed $n l$, of an ISW is usually quantified as $n l=a_{\max } / h$, where $\mathrm{h}$ is a relevant depth scale. This measure corresponds to the definition of nonlinearity that arises when deriving the $\mathrm{KdV}$ model from the nonlinear Euler equations [e.g., Helfrich and Melville, 2006]. Only if nonlinearity is small $(n l \ll 1)$ is the application of KdV theory mathematically justified, in which case the ISWs are called weakly nonlinear. In a two-layer system, consisting of a clearly separated upper and a deep lower layer, the simplest choice of relevant depth is the upper layer depth, which is widely used to derive the degree of nonlinearity [e.g., Grue et al., 1999; Helfrich and Melville, 2006; Helfrich and White, 2010].

[18] The choice of the relevant depth in a continuous stratification is not as straightforward because a clear identification of an upper layer is not possible (Figure 3). There are, however, two depths in a continuous stratification, which resemble the upper layer depth in a two-layer system with a thin thermocline separating the upper and lower layer: the thermocline depth $h_{t}$ itself, defined as the depth where the density gradient is largest, and the propagation depth $H_{p}$. Propagation depth and thermocline depth are very similar in a two-layer system with a thin thermocline [Lamb and Nguyen, 2009]. In continuous stratification both depths can differ significantly (Figure 2a). Since both depths might be appropriate for estimating the degree of nonlinearity of the ISWs propagating in continuous stratification, we consider two different nonlinearity indices: the index resulting from the thermocline depth, $n l_{t}=a_{\max } / h_{t}$ and the index resulting from the propagation depth, $n l_{p}=a_{\max } / H_{p}$.

[19] Note that these indices are deep water approximations and require small ratios $h_{t} / H$ or $H_{p} / H$, where $H$ is the total water depth. Since our data were measured at the deepest location of Lake Überlingen with $140 \mathrm{~m}$ water depth and $h_{t}$ or $H_{p}$ ranged typically between 5 and $20 \mathrm{~m}$, the ratios were typically smaller than 0.15 and thus are much smaller than 1. For larger ratios $h_{t} / H$ or $H_{p} / H$ the water depth influences the degree of nonlinearity. In this case the water depth could be incorporated in the index characterizing the nonlinearity of ISWs. Aghsaee et al. [2010] suggested a nonlinearity index of

$$
n l_{t} \cong \frac{a_{\text {max }}}{h_{t}} \frac{H-2 h_{t}}{H-h_{t}}
$$

in a two-layer fluid. Adopting their suggestions, $n l_{p}$ might be generalized by choosing

$$
n l_{p}=\frac{a_{\max }}{H_{p}} \frac{H-2 H_{p}}{H-H_{p}} .
$$

However, in our case these generalized formulas led to almost identical results as the deep water approximations.

[20] Density inversions occurring in the center of ISWs indicate overturns and therefore shear or convective instability (Figure 2a). Note that just from evaluating the temperature data, it is usually not possible to decide whether a wave accompanied by temperature inversions is shear or convective unstable. We considered inversions across which the temperature increased by more than $0.02^{\circ} \mathrm{C}$ with depth, a value well above the accuracy limit of the thermistors, and if they occurred between the propagation depth (and at least $4 \mathrm{~m}$ depth) and $50 \mathrm{~m}$ to exclude inversions generated in the mixed surface layer or the bottom boundary layer. The degree of instability of a single wave or a wave train was estimated by counting the number of unstable density profiles during the passage of a wave or a wave train within the first $2 \mathrm{~h}$ of passage. A wave or wave train was called unstable if the degree of instability was larger than one. A wave train is thus unstable if it contains at least one unstable wave. As a measure of the vertical range of the instabilities within an ISW, the maximum of the depth differences, spanned by inversions occurring at the same time within the leading ISW, was calculated (red arrows in Figure 2b).

\subsection{Models}

[21] In order to evaluate to what extent seasonality of ISW properties is driven by stratification, we simulate ISW 
properties by applying the $\mathrm{KdV}$ and the DJL models. Instead of simulating individual ISWs, we confined the simulations to the typical seasonal stratifications shown in Figures 3a and $3 \mathrm{~b}$. This procedure illustrates how ISW properties depend on the background stratification. The comparison between $\mathrm{KdV}$ - and DJL-simulated seasonal wave properties is employed to support the distinction between weakly and strongly nonlinear ISWs.

\subsubsection{Stratified KDV Model}

[22] First mode weakly nonlinear internal waves were simulated using analytical ISW solutions of the stratified $\mathrm{KdV}$ equation [see, e.g., Ostrovsky and Stepanyants, 2005, and references therein]:

$$
\eta(x, z, t)=-a_{\max } \operatorname{sech}^{2}\left(\frac{x-c t}{\lambda}\right) W_{0}(z),
$$

where $\eta(x, z, t)$ is the vertical displacement of the isotherm passing through location $x$ at time $t$ relative to its depth $z$ at rest, $a_{\max }$ is the ISW amplitude, $\lambda=\left(12 / a_{\max } \beta / \alpha\right)^{1 / 2}$ is the vertically independent wavelength, and $c=c_{0}+a \alpha / 3$ is the phase speed. Note that $\lambda$ describes the equivalent square wavelength as defined, for example, by Vlasenko et al. [2000]. The linear phase speed $c_{0}$ and the function $W_{0}$ are the eigenvalue and eigenfunction corresponding to the first mode of the boundary value problem

$$
\begin{aligned}
& \left(\rho W_{z}\right)_{z}+\frac{\rho N^{2}}{c_{0}^{2}} W=0 \\
& \text { with } W(0)=W(H)=0,
\end{aligned}
$$

where $N$ is the Brunt-Väisälä frequency and $\rho$ the undisturbed density profile. The parameters $\alpha$ and $\beta$ are given by [Ostrovsky and Stepanyants, 2005]

$$
\alpha=\frac{3 c_{0} \int_{-H}^{0} \rho W_{z}^{3} d z}{2 \int_{-H}^{0} \rho W_{z}^{2} d z}, \quad \beta=\frac{c_{0} \int_{-H}^{0} \rho W^{2} d z}{2 \int_{-H}^{0} \rho W_{z}^{2} d z} .
$$

\subsubsection{Dubreil-Jacotin-Long Model}

[23] Strongly nonlinear internal waves were found by numerically solving the DJL equation in a Boussinesq fluid of depth $H$ [cf. Stastna and Lamb, 2002]:

$$
\begin{aligned}
& \nabla^{2} \eta+\frac{N^{2}(z-\eta) \eta}{c^{2}}=0 \\
& \text { with } \eta\left(x^{\prime}, 0\right)=\eta\left(x^{\prime}, H\right)=0
\end{aligned}
$$

where $\eta=\eta\left(x^{\prime}, z\right)=\eta(x-c t, z)$ is the vertical displacement of the isotherm passing through $(x, z)$ relative to its depth at rest with $z=H$ at the surface (compare Lamb [2002] and Stastna and Lamb [2002]). The numerical code for solving this equation was provided by M. Stastna and is described in detail by Stastna and Lamb [2002].

\subsubsection{Estimation of Model Parameters}

[24] ISWs were measured at a distance of about $9 \mathrm{~km}$ from the western end of Lake Überlingen and $12 \mathrm{~km}$ from the Sill of Mainau. ISWs propagating into Lake Überlingen are assumed to be generated when the basin-scale seiche steepens into a nonlinear internal surge [de la Fuente et al., 2010]. The occurrence of the surge is typically linked to strong wind events coming from west-southwest [Appt et al., 2004], which are the prevailing winds in Lake Constance
(Figure 1c). Moreover, ISWs were also observed to travel in the opposite direction accompanying the front after it had been reflected at the end of Lake Überlingen [Preusse et al., 2010]. In both directions, the waves propagate for at least $5 \mathrm{~km}$ in water of depth ranging from $100 \mathrm{~m}$ to $140 \mathrm{~m}$ before passing the measuring station (Figure 1a). For the modeling, we replace this slowly varying depth by its mean, $125 \mathrm{~m}$ (for the averaging region, see Figure 1b).

[25] In order to obtain typical seasonal density profiles (SDPs) for the simulations, we first identify background stratifications associated with individual wave trains. The background stratification of each wave train is defined as the 1-h mean temperature profile obtained by averaging over the time interval from $70 \mathrm{~min}$ to $10 \mathrm{~min}$ before the passage of the train's first ISW. In the following, these profiles are called ISW background temperatures. The typical SDPs used for simulation (Figure 3a) were generated by averaging the individual ISW background temperature profiles corresponding to the same month and applying the Chen-Millero formulas to obtain the water density [Chen and Millero, 1986]. The Brunt-Väisälä frequency was estimated by applying $2 \mathrm{~m}$ centered differences (and backward or forward differences on the edges) to the SDPs (Figure 3b). The simulated waves, which are modeled by choosing the parameters on the basis of the SDPs (Figures $3 \mathrm{a}$ and $3 \mathrm{~b}$ ), will be called seasonal prototypes. A seasonal prototype is therefore the typical (in terms of mean) wave one would expect to propagate during a certain month.

\section{Results}

\subsection{Individual Waves}

[26] The total of 219 observed wave trains span a wide range of characteristic values of ISW properties. The properties, which are number of waves per train, amplitude, propagation depth, period, number of inversions contained in a wave train, vertical instability range of the leading ISW, time span between consecutive wave trains, and nonlinearity indices $n l_{t}$ and $n l_{p}$ were analyzed in detail (Figure 4). Most of these properties are clearly not normally distributed (Lilliefors test, $\mathrm{p}<0.01$ ). However, the test cannot clarify whether propagation depths and periods are from a normal distribution.

\subsubsection{Nonlinearity}

[27] Both measures of nonlinearity, $n l_{t}$ and $n l_{p}$, can be evaluated to estimate the percentage of strongly nonlinear waves in Lake Constance. In a continuous stratification, as given here, these measures are not exchangeable (Figure 5) because $n l_{t}$ and $n l_{p}$ are not strongly correlated $\left(\mathrm{R}^{2}=0.26\right.$, $\mathrm{p}<0.01$ and $\mathrm{R}^{2}=0.42, \mathrm{p}<0.01$, for the logarithmic values). Note that these measures contain more information than just amplitude $\left(\mathrm{R}^{2}=0.39, \mathrm{p}<0.01\right.$ and $\mathrm{R}^{2}=0.33$, $\mathrm{p}<0.01$ for the correlation between amplitude and $n l_{t}$ or $n l_{p}$, respectively) because they combine ISW amplitude with thermocline depth or propagation depth, respectively.

[28] Clearly, waves can be considered strongly nonlinear if they are unstable. We found a total of $36(16 \%)$ leading waves and $55(25 \%)$ wave trains accompanied by density inversions, where 33 (15\%) leading waves and $45(21 \%)$ wave trains were associated with more than one inversion and hence are classified as unstable. The nonlinearity index $n l_{p}$ clearly separates unstable leading ISWs or wave trains 

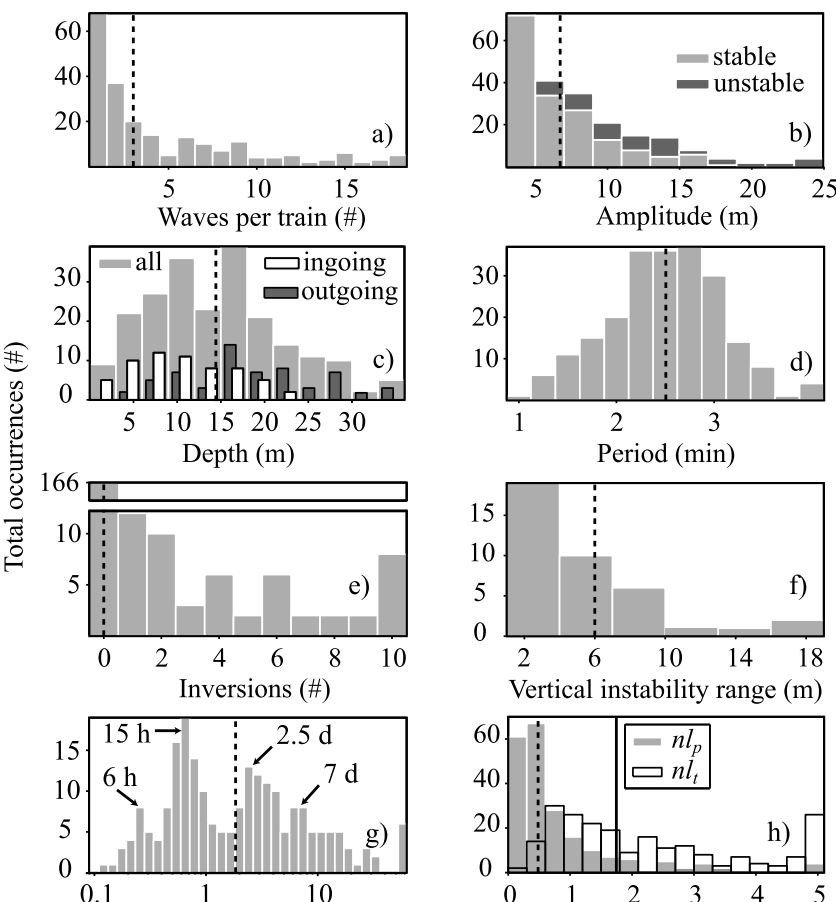

Delay between wave trains (days)

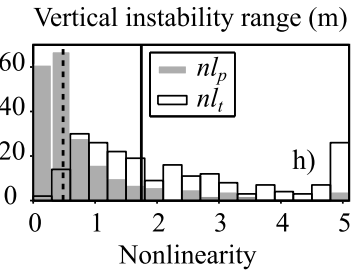

Figure 4. ISW properties. Distributions of the (a) number of waves per train, (b) amplitude of stable (light bars) and unstable (dark bars) waves, (c) propagation depth of all waves and of ingoing (light bars) and outgoing (dark bars) waves which could be classified (see text), (d) wave periods, (e) number of unstable density profiles per wave train, (f) vertical instability range of the leading solitary wave (neglecting zeros), (g) time span between wave trains, and (h) nonlinearity indices $n l_{t}$ (light bars) and $n l_{p}$ (dark bars). Dashed lines indicate the median.

from stable waves (Figure 5). Inversions in some cases result from wave breaking (Figure 6a), a process probably accompanied by a considerable amount of thermocline mixing. In other cases density inversions arise from waves with trapped cores (Figure 6b).

[29] The nonlinearity index $n l_{p}$ of the leading ISW is very reliable in distinguishing wave trains according to their probability of instability. This is clearly demonstrated by the empirical distribution function of $n l_{p}$ (Figure 7). Defining lower and upper thresholds of $n l_{p}, c_{l}\left(n l_{p}\right)$ and $c_{u}\left(n l_{p}\right)$, such that below $c_{l}\left(n l_{p}\right)$ more than $95 \%$ (or alternatively more than $90 \%)$ of the wave trains are stable and above $c_{u}\left(n l_{p}\right)$ more than $95 \%(90 \%)$ of the wave trains are unstable, one obtains $c_{l}\left(n l_{p}\right)=0.8(1.65)$ and $c_{u}\left(n l_{p}\right)=4.7(3.2)$. Using these threshold values of $n l_{p}$ as a criterion, the stability of $70 \%$ $(80 \%)$ of all observed wave trains can be adequately identified. If stability analysis is based on amplitude alone, the lower and upper thresholds of amplitude corresponding to the definition of $c_{l}\left(n l_{p}\right)$ and $c_{u}\left(n l_{p}\right)$ are $c_{l}\left(a_{\max }\right)=6 \mathrm{~m}(8.5 \mathrm{~m})$ and $c_{u}\left(a_{\text {max }}\right)=19 \mathrm{~m}(17.5 \mathrm{~m})$ (Figure $\left.4 \mathrm{~b}\right)$. With these thresholds, amplitude allows stability to be determined in only $50 \%(75 \%)$ of the observed wave trains. The nonlinearity index $n l_{t}$ with the corresponding lower and upper thresholds of 1.1 (1.5) and 16.2 (16.2), respectively, is only capable of characterizing stability adequately in 30\% (55\%) of all wave trains. The index $n l_{p}$ is thus the most efficient parameter for classifying unstable waves. Note that $n l_{p}$ predicts the probability of instability even more accurately for the leading ISW than for the wave train: $99 \%$ of the waves are stable below the lower threshold $c_{l}\left(n l_{p}\right)=0.8$ and $99 \%$ of the waves are unstable above the upper threshold $c_{u}\left(n l_{p}\right)=4.7$.

[30] Our results are consistent with observations in the laboratory, where the upper layer depth was used as relevant depth scale to estimate $n l$ (Figure 7). Grue et al. [2000] observed the occurrence of wave breaking at $n l \geq 0.65$ in a continuously stratified fluid composed of a layer of constant density gradient overlying a layer of constant density (see also stability threshold in Figure 5). The stability threshold in these laboratory experiments is close to the $99 \%$ stability threshold $c_{l}\left(n l_{p}\right)=0.8$ for the leading ISW and $n l_{p}=0.575$ for the wave train determined from our field measurements (see Figure 7). This good agreement suggests that thresholds for weakly nonlinear waves, obtained from laboratory experiments in two-layer stratification, may also be conferrable to field conditions. In several experiments it was found that $\mathrm{KdV}$ theory is applicable far above the mathematical range of validity of $n l \ll 1$ to moderate-amplitude ISWs [Helfrich and Melville, 2006; Ostrovsky and Stepanyants, 2005]. Good agreement between two-layer theory and experiments were obtained for example for wave amplitudes as large as $n l \leq 0.4$ [Grue et al., 1999]. Applying this threshold to our measurements suggests that a total of $60 \%$ of the observed ISWs have to be treated as strongly nonlinear (Figure 7).

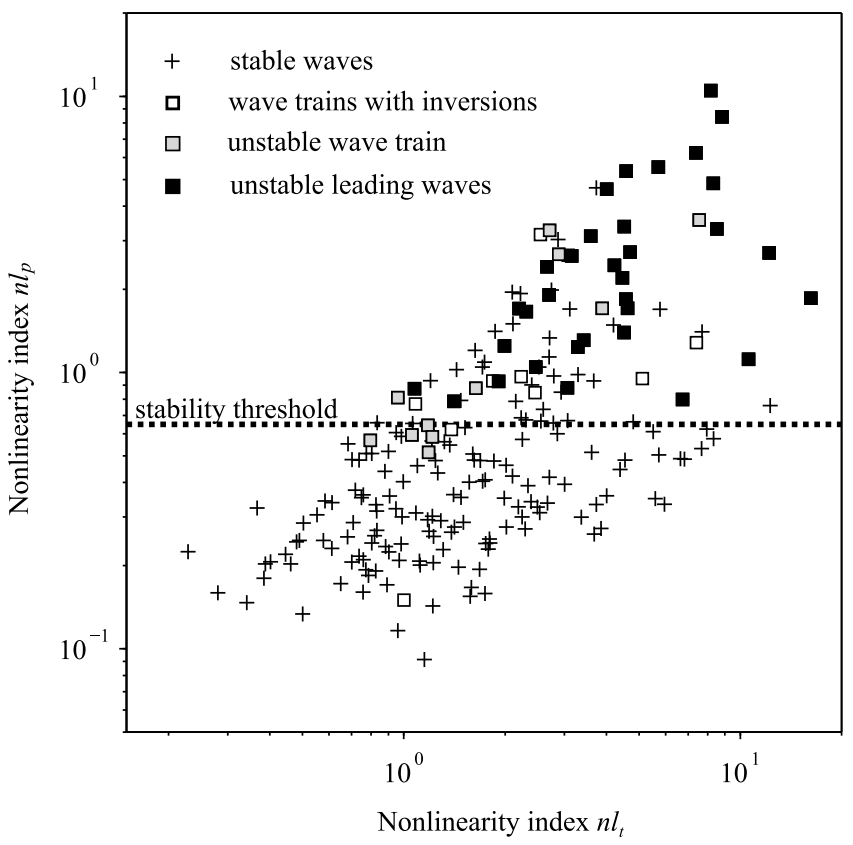

Figure 5. Relation between nonlinearity indices $n l_{t}$ and $n l_{p}$ on a logarithmic scaling. Crosses correspond to observations of ISWs without density inversions, squares to unstable ISWs (black) or wave trains accompanied by one (white) or more than one (gray) inversion. The line marks the stability threshold 0.65 . 


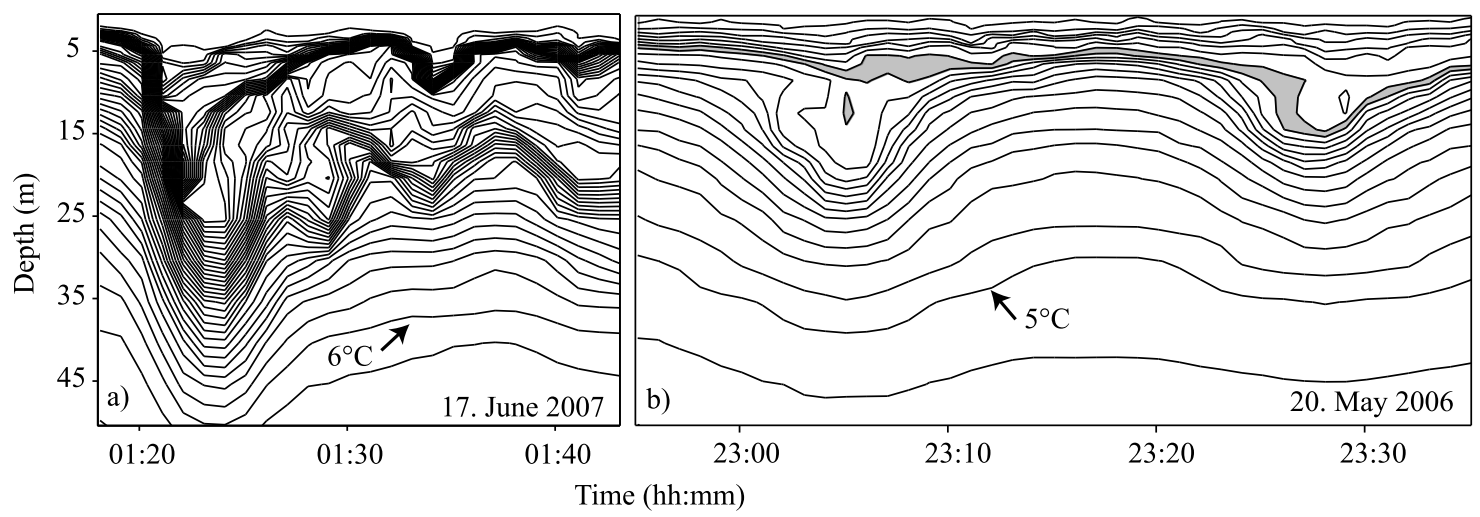

Figure 6. Isotherms with a $0.25^{\circ} \mathrm{C}$ resolution showing that inversions can result from different phenomena: (a) wave breaking (isotherms range from $5.75^{\circ} \mathrm{C}$ to $17.5^{\circ} \mathrm{C}$ ) and (b) trapped cores (isotherms range from $4.75^{\circ} \mathrm{C}$ to $9.75^{\circ} \mathrm{C}$ ). The area between $8^{\circ} \mathrm{C}$ and $8.25^{\circ} \mathrm{C}$ is shaded gray.

\subsubsection{Wave Types}

[31] Before examining the role of seasonal changes in stratification for the properties of ISWs, we analyze the waves individually to determine factors other than stratification that influence the wave characteristics. For example, different generation mechanisms can result in varied wave properties, as was observed on the continental shelf of the Middle Atlantic Bight [Zheng et al., 2007].

[32] For every wave train, we considered its delay, i.e., the time that had elapsed since the passage of the previous wave train. A comparison of the delays reveals a highly discrete pattern (Figure 4g). Except for the cluster corresponding to a time delay of $6 \mathrm{~h}$, the peaks are connected to typical time scales associated with the internal seiche. The cluster corresponding to a delay between 2.5 and 4 days reflects the period of the first vertical and first horizontal mode internal seiche, which typically has a mean period of about 4 days in autumn [Bäuerle et al., 1998]. The cluster around the 6 to 8 day delay corresponds to a double seiche period, suggesting that not each cycle of the seiche is necessarily connected to ISW trains. Nevertheless, $50 \%$ of the wave trains were observed with delays of $48 \mathrm{~h}$ at most, which is shorter than the typical seiche period.

[33] Approximately 25\% of wave trains correspond to the cluster around the $15 \mathrm{~h}$ delay time. These waves travel with the front of the basin scale seiche after it has been reflected at the end of Lake Überlingen. Assuming typical phase velocities of the internal front between 0.2 and $0.5 \mathrm{~m} / \mathrm{s}$, ISWs propagating with the reflected front (outgoing ISWs) would pass our measuring station in central Lake Überlingen between 9 and $25 \mathrm{~h}$ after the observation of ISWs that are associated with the front entering Lake Überlingen from the main basin (ingoing ISWs).

[34] Waves associated with a delay time smaller than $9 \mathrm{~h}$ often follow waves with a delay of about several days and pass before a wave train with a delay of around $15 \mathrm{~h}$. The $6 \mathrm{~h}$ peak suggests either differences in the generation mechanisms of the waves or an artificial separation of waves

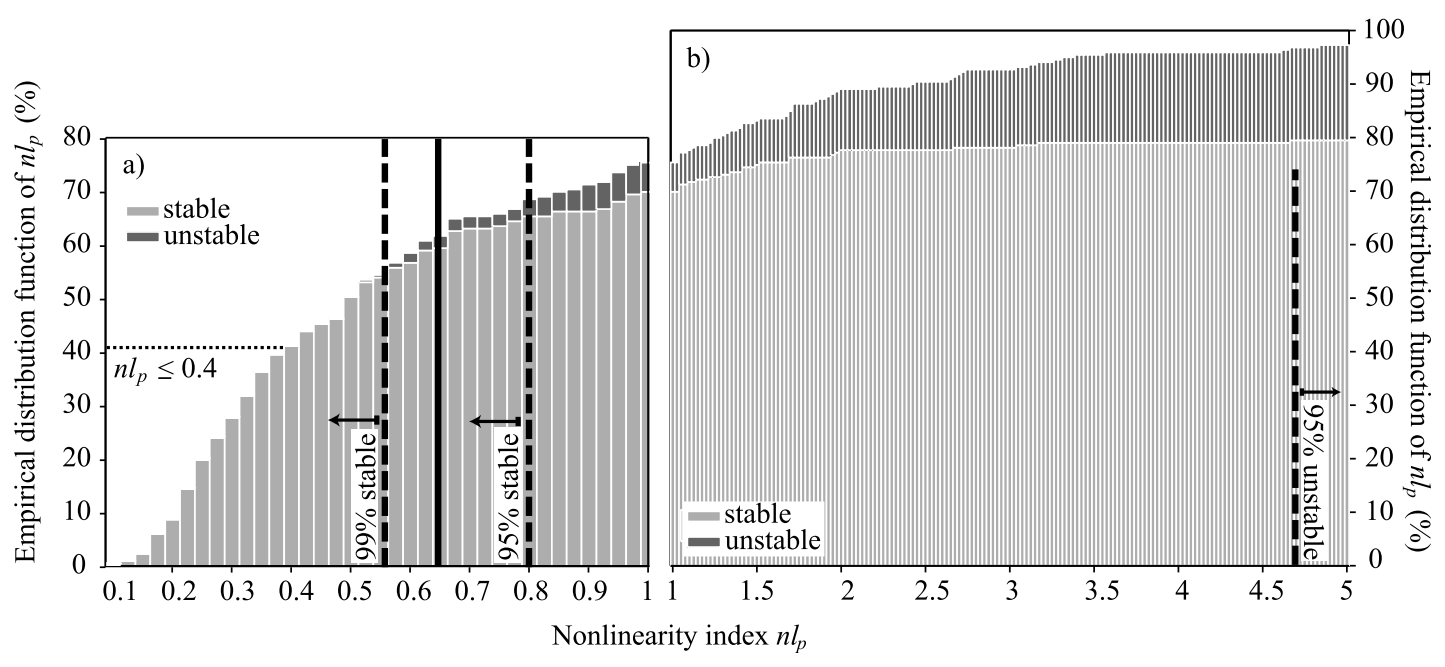

Figure 7. Empirical distribution function of nonlinearity index $n l_{p}$ for (a) small $n l_{p}$ and (b) large $n l_{p}$. Note the different scaling of the $x$ axis. The dashed lines illustrate the measured $95 \%$ and $99 \%$ stability and $95 \%$ instability thresholds for a wave train (see text). The solid line indicates the stability threshold $\left(n l_{p} \leq 0.65\right)$ for an individual ISW and the dotted lines indicate the percentage of weak nonlinear waves $\left(n l_{p} \leq 0.4\right)$ according to laboratory results. Light and dark bars refer to stable and unstable wave trains, respectively. 
Table 1. Wave Characteristics of Ingoing and Outgoing Internal Solitary Waves ${ }^{\mathrm{a}}$

\begin{tabular}{|c|c|c|c|c|c|c|}
\hline \multirow[b]{2}{*}{ Properties } & \multicolumn{2}{|c|}{ Ingoing } & \multicolumn{2}{|c|}{ Outgoing } & \multirow[b]{2}{*}{$R^{2}(\%)$} & \multirow[b]{2}{*}{$p$} \\
\hline & Mean & Median & Mean & Median & & \\
\hline$H_{p}(\mathrm{~m})$ & 11 & 11 & 19 & 19 & 27 & $<0.01$ \\
\hline$n l_{p}$ & 1.4 & 0.8 & 0.6 & 0.4 & 13 & $<0.01$ \\
\hline$a_{\max }(\mathrm{m})$ & 8.9 & 8.1 & 8.7 & 7.1 & & $>0.05$ \\
\hline$T(\min )$ & 2.3 & 2.2 & 2.6 & 2.5 & 6 & $<0.01$ \\
\hline Waves/train (\#) & 7 & 6 & 5 & 2 & 4 & $<0.05$ \\
\hline
\end{tabular}

${ }^{\mathrm{a}}$ Mean and median values of propagation depth $H_{p}$, nonlinearity index $n l_{p}$, amplitude $a_{\max }$, period $T$, and number of waves per train. Correlation coefficients $R$ and significance $p$ correspond to a correlation between wave property and wave type given as nondimensional values 1 and 2 .

corresponding to the same wave train due to malformed ISWs (see section 2.2.2). A closer analysis of the data revealed a rather rare third wave type in the lead of ingoing and outgoing ISWs (e. g. Figure 2a, ISW3). However, owing to the broad distribution of delay times, it was not possible to distinguish this type of ISWs in the delay patterns.

[35] ISWs with a delay time between 9 and $25 \mathrm{~h}$ compared to the passage of the previous wave train were identified as outgoing ISWs. ISWs observed before the outgoing ISWs passed the measuring station were categorized as ingoing waves. Using this criterion, $55 \%$ of all ISWs could be characterized either as ingoing or outgoing waves. Ingoing and outgoing waves have different properties (Figure $4 \mathrm{c}$ and Table 1), since they propagate in different background stratifications generated by the steepened internal seiche. Ingoing ISWs typically pass shortly before an internal surge, which transports warm water into Lake Überlingen (Figure 2a, ISWs1, ISWs4, ISWs6). The outgoing ISWs (Figure 2 a, ISWs2, ISWs5) propagate in the stratification modified by the incoming surge. Consequently, the background stratification valid for the outgoing ISWs is characterized by isothermal depths that are lower than those prior to the passage of ingoing ISWs.

[36] Ingoing ISWs propagate at a mean depth of $11 \mathrm{~m}$, outgoing ISWs at a mean depth of $19 \mathrm{~m}$. Moreover, the propagation direction explains about $30 \%$ of the variation of propagation depth $\left(\mathrm{R}^{2}=0.27, \mathrm{p}<0.01\right)$. Owing to the differences in propagation depth, $70 \%$ of the ingoing ISWs are above the stability boundary (median $n l_{p}=0.8$ ), whereas $50 \%$ of the waves at the reflected front are weakly nonlinear (median $n l_{p}=0.4$ ). This is confirmed by the number of density inversions that were significantly more frequent in ingoing $(33 \%)$ than in outgoing $(15 \%)$ waves. The wave properties amplitude and period are similar for ingoing and outgoing waves (Table 1). For the seasonal prototypes described in the next subsection no distinction was thus made between ingoing and outgoing waves.

\subsection{Seasonal Prototypes}

[37] As shown in Figure 3, the stratification changes over the year. In particular, the ISW background Brunt-Väisälä frequency $N$ (Figure $3 \mathrm{~b}$ ) is largest in summer and the vertical peak of $N$ is deepest in autumn.

\subsubsection{Seasonally Varying Properties}

[38] In Lake Constance, ISWs occur between April and October (Table 2). Note that the absolute values stated in Table 2 are an underestimation of the wave trains that actually occurred during the 6 measuring years because of gaps in the data and because not all waves matched the requirements of the fitting routine. ISWs also occurred sporadically in November, but their total number was smaller than in October. Since statistics of such a small number of waves would not be representative, these ISWs were excluded from the statistical analysis.

[39] A careful analysis of the seasonality of ISWs demonstrates that some properties depend on season and some do not (Figure 8). The seasonal variation of stratification resulted in a seasonally unequal frequency of occurrence of ISWs, with high ISW densities occurring especially during July (Figure 8b) when the background Brunt-Väisäläfrequency was maximal (Figure 2b). In order to estimate the number of individual ISWs typically generated in a single cycle of the basin-scale seiche, we define an ISW complex as the composition of all wave trains corresponding to the same (usually entering and then reflected) front. Because the front is typically generated by steepening of the basin-scale seiche before entering Lake Überlingen, ISW complexes can be identified based on delay times between consecutive wave trains that are larger than 1.5 days (see section 3.1.2). With the exception of October, on average two ISW trains per ISW complex were observed (Figure 8b), where an ISW train usually consists of more than three individual ISWs (Figure 8a, median). Since the percentage of ingoing versus outgoing ISWs hardly changes over the year, apart from in October, it can be assumed to have no noticeable influence on the seasonal dependence of the wave properties. A KruskalWallis test is thus applicable within this time frame to determine whether the median properties depend significantly on season $(\mathrm{p}<0.05)$. A $t$-test for determination of $95 \%$ confidence intervals on the mean properties is only justified for depth and period, which might be normally distributed (see section 3.1) as is suggested by the similarity of mean and median.

[40] The median number of waves per train differs significantly over the year (Figure 8a). With approximately three waves, the trains are largest during summer and early autumn, except for the trains in August. Median propagation depths increase significantly with season, from $10 \mathrm{~m}$ in spring to $20 \mathrm{~m}$ in autumn (Figure $8 \mathrm{~d}$ ). This behavior reflects the increase of thermocline depth over the year (Figure 3b). Furthermore, median nonlinearity indices change significantly (Figure 8f). Median values above the stability threshold of 0.65 appear only in spring, indicating that ISWs are especially nonlinear during this period. In summer and autumn median values are usually located somewhat above the threshold for weakly nonlinear waves. The particularly

Table 2. Number of Total Observations of Internal Solitary Wave Trains

\begin{tabular}{lc}
\hline Property & Total Number of Occurrences \\
\hline Apr & 6 \\
May & 25 \\
Jun & 40 \\
Jul & 64 \\
Aug & 43 \\
Sep & 34 \\
Oct & 6 \\
\hline
\end{tabular}



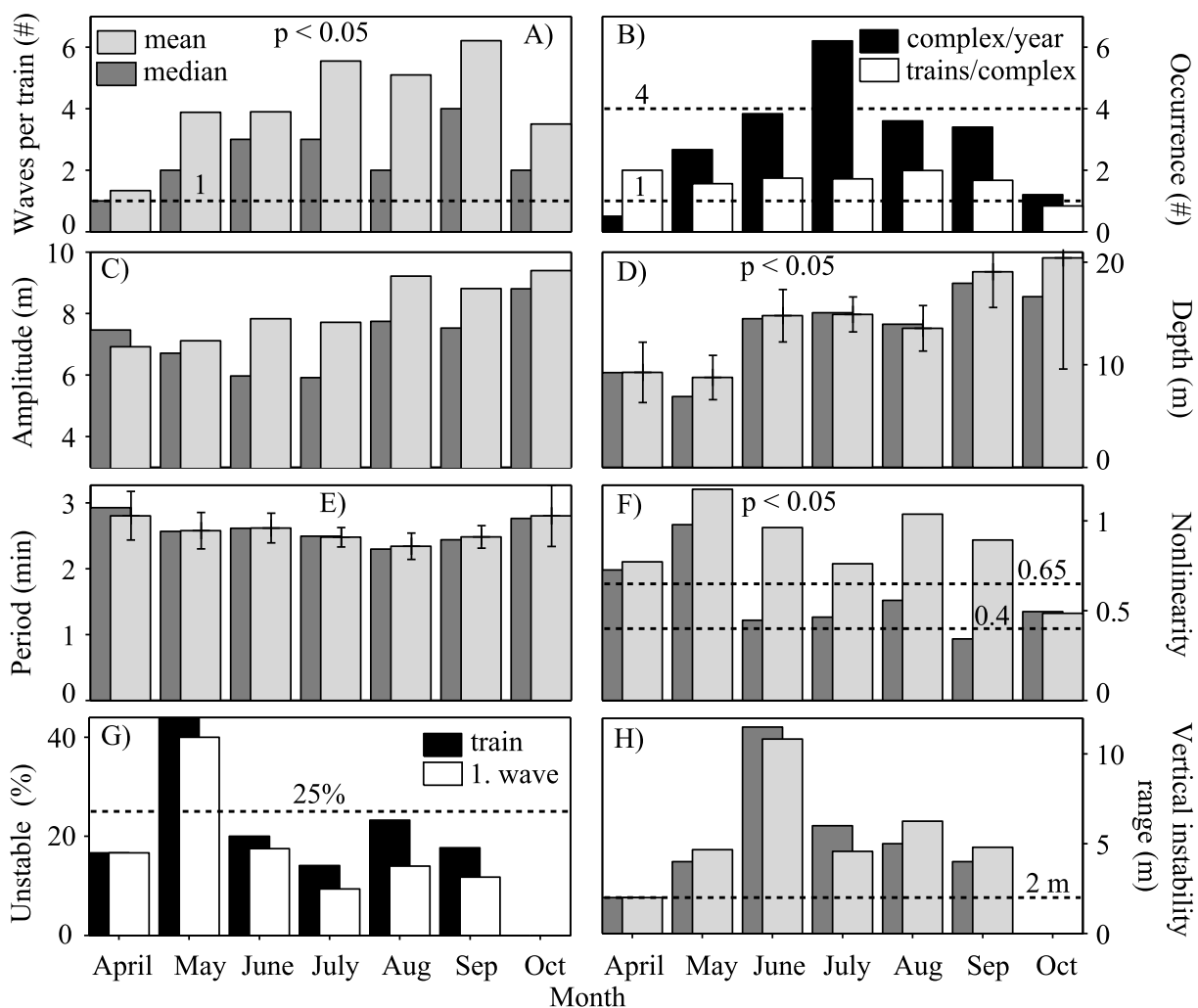

Figure 8. Season-dependent solitary wave properties: (a) mean and median number of waves per train, (b) mean number of wave complexes (black) and trains per complex (white), (c) mean and median amplitude, (d) mean and median propagation depth, (e) mean and median period, (f) mean and median nonlinearity, $(\mathrm{g})$ percent of unstable wave trains (black) and leading waves (white), and (h) mean and median vertical range of instabilities. Mean and median values are depicted in light and dark gray, respectively. Confidence intervals of $95 \%$ on the mean are calculated for depth and period ( $t$-test).

large percentage of unstable ISWs during May corresponds to the high median nonlinearity index (Figure 8g). Additionally, the slightly larger wind speeds in spring (Figure 1c) and the weak stratification could have contributed to the enhanced occurrence of density inversions. From June to September, the percentage of unstable waves and trains scatters around $20 \%$. Note that the number of waves observed during April and October is too small (Table 2) to provide a reliable value.

[41] Median amplitudes, even if the means increase with season, do not vary significantly and range between 6 and $9 \mathrm{~m}$. Median periods (between 2 and $3 \mathrm{~min}$ ) and the vertical depth range in which instabilities occur (between 1 and $12 \mathrm{~m}$ ) are also statistically not distinguishable over the year.

\subsubsection{Modeling Seasonal Properties}

[42] In order to evaluate the choice of $n l_{p} \leq 0.4$ as the boundary for weakly nonlinear waves, seasonal prototypes simulated by DJL and KdV are compared with each other and with monthly averaged measured ISW profiles of amplitudes and periods of isothermal displacements, $\bar{a}_{i}(z)$ and $\bar{T}_{i}(\mathrm{z})$, respectively, given by

$\bar{a}_{i}(z)=\left(\frac{1}{n^{i}} \sum_{k=1}^{n^{i}} a_{\max _{i, k}}\right)\left(\frac{1}{n^{i}} \sum_{j=1}^{n^{i}} \frac{a_{i, j}(z)}{a_{\max _{i j}}}\right), \bar{T}_{i}(z)=\left(\frac{1}{n^{i}} \sum_{j=1}^{n^{i}} T_{i, j}(z)\right)$, where $i$ corresponds to a month between April and October and $n^{i}$ is the number of leading waves in month $i$. The weighting of the displacement profiles reduces the influence of extremely large amplitude waves on $\bar{a}_{i}(z)$. Applying an un-weighted average would, however, lead to qualitatively similar results. The profiles $\bar{a}_{i}(z)$ and $\bar{T}_{i}(\mathrm{z})$ determined from the measured ISWs change over the year (Figure 9, markers). The monthly, weighted averaged profiles $\bar{a}_{i}(z)$ show an increase in propagation depth from spring to autumn and large nonlinearity indices $n l_{p}$ in spring, which are both in agreement with the statistical results obtained by averaging the wave properties independently (Figures 8e and 8f).

[43] Simulating the seasonal ISW prototypes based on the seven typical seasonally varying stratifications shown in Figures 3a and 3d by KdV (broken lines, Figure 9) and DJL (solid lines, Figure 9) describes the weighted averaged vertical profiles $\bar{a}_{i}(z)$ for the observed ISWs well. The prototypes reflect the seasonal dependence of propagation depth and nonlinearity index qualitatively. As the simulations differ only in the stratification considered, they indicate that the observed seasonality of nonlinearity and propagation depth is caused by seasonal change in stratification. Both models strongly underestimate $\bar{T}_{i}(\mathrm{z})$. This underestimation could be a result of the linear averaging approach, since the periods of ISWs typically decrease nonlinearly with amplitude [Stastna and Lamb, 2002; Vlasenko et al., 2000]. 

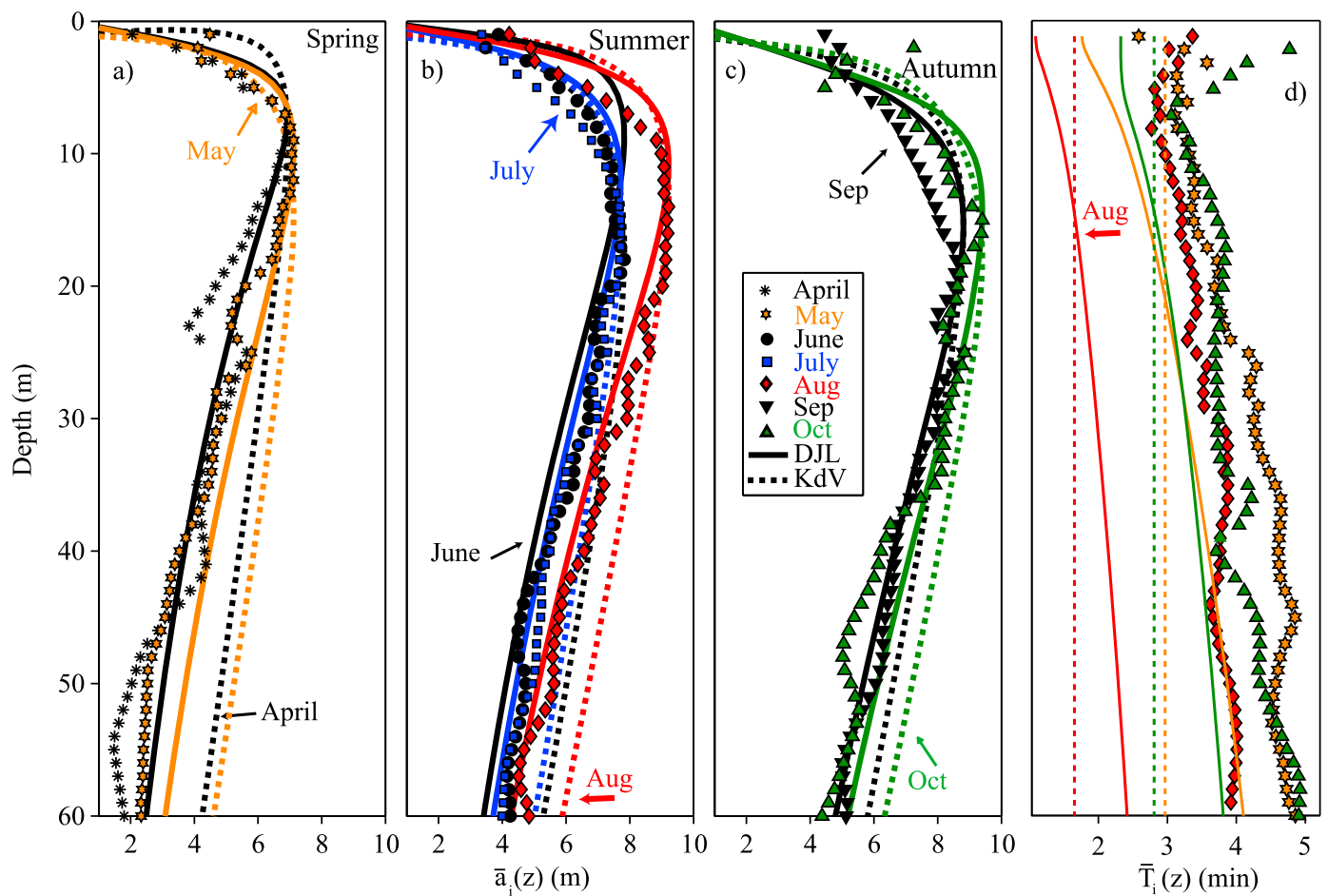

Figure 9. Comparison of observed and simulated $\bar{a}_{i}(z)$ in the months of (a) spring, (b) summer, and (c) autumn, respectively, and (d) $\bar{T}_{i}(\mathrm{z})$ in May, August, and October. Markers correspond to monthly averaged measured profiles and solid and broken lines correspond to simulations with DJL and KdV, respectively, using the mean ISW background stratification in the respective month (see Figures $3 \mathrm{a}$ and $3 \mathrm{~b}$ ).

Linearly averaging the observed $T_{i j}(z)$ profiles thus overestimates the $T(z)$ profile corresponding to a wave with mean amplitude that was used for the simulations. In addition, these nonlinear effects are known to depend on stratification. The particularly large deviations in summer, exemplified for August in Figure 9d, might result from an especially strong nonlinear decrease in the relevant amplitude range during this season.

[44] A comparison between DJL and $\mathrm{KdV}$ simulations of the vertical ISW properties demonstrates that the overall vertical structures of $\bar{a}_{i}(z)$ (Figures $8 \mathrm{a}-8 \mathrm{c}$ ) and $\bar{T}_{i}(\mathrm{z})$ (Figure 9d) are much more closely predicted by DJL. The vertical profiles simulated by KdV and DJL also differ in September. September is the only month when the observed median $n l_{p}$ (Figure 8f) and $n l_{p}$ determined from $\bar{a}_{i}(z)$ falls below the boundary of 0.4 for weakly nonlinear waves. The differences between $\mathrm{KdV}$ and DJL prototypes suggest that $n l_{p} \leq 0.4$ is a rather generous threshold for weakly nonlinear waves.

\section{Discussion}

[45] Our analysis of 219 ISW trains, observed between 2004 and 2010 with the exception of 2008, shows not only that ISW trains occur very regularly in Lake Constance but also demonstrates that a substantial proportion of waves with amplitudes larger than $3 \mathrm{~m}$ are strongly nonlinear. Moreover, at least $20 \%$ of the total number of wave trains and $15 \%$ of the leading ISWs are associated with density overturns. Since temperature was sampled only once a minute and the current velocities at the study site are unknown, the individual mechanisms generating the overturns could not be identified. However, we found evidence of both active wave breaking and ISWs with trapped cores. These processes have different ecological consequences. ISW breaking causing strong localized turbulence in the lakes interior can result in spatially and temporally highly variable mixing in the pelagic thermocline [Preusse et al., 2010]. Sporadic mixing events can induce vertical fluxes of nutrients from the hypolimnion to the epilimnion that may initiate plankton patchiness [Mackas et al., 1985]. Waves with trapped cores, on the other hand, may transport entrained particles over long distances. For example, ISWs with trapped cores were observed to transport material from the seabed onshore [Klymak and Moum, 2003], when they occur as waves of elevation. Similarly, ISWs of depression could include material from the epilimnion into a core and transport it horizontally [Helfrich and White, 2010]. In this way larvae, for example, might be distributed through the lake [Pineda, 1999]. To our knowledge there have been no clear observations of trapped core waves of depression in the pelagic zone of oceans or lakes up to now (but see Farmer et al. [2011]). However, a combination of numerical simulations and observations from the ocean [Lamb and Farmer, 2011], laboratory experiments [Carr et al., 2008], and purely numerical investigations [Helfrich and White, 2010; Stastna and Lamb, 2002] suggests that ISWs of depression with trapped cores may exist in the field. Our observations in Lake Constance (Figure 6b) of ISWs carrying a patch of lighter fluid enveloped by denser fluid indicate that ISWs of depression with core-like structures can occur in lakes. 
[46] The probability for a certain ISW to be unstable was reliably estimated by the nonlinearity index $n l_{p}$, which is based on the propagation depth of the ISWs as relevant depth scale. Estimating the instability of ISWs by applying the thermocline depth, instead of the propagation depth, as the depth scale, i.e., using $n l_{t}$ instead of $n l_{p}$, describes the probability of instability less well than the amplitude alone would. Thus in the case of highly nonlinear waves in continuous stratification, $n l_{p}$ is a better parameter for predicting the strength of the nonlinearity than $n l_{t}$. In three-layer systems, in which the thermocline thickness is smaller than the upper layer thickness ISW breaking can be estimated from simple formulas based on the layer thicknesses [Bogucki and Garrett, 1993; Fructus et al., 2009]. However, in deep temperate lakes the thermocline can extend up to the surface such that no or only a very small upper mixed layer exists. The index of nonlinearity, $n l_{p}$, employed to predict wave breaking in such stratification cannot be derived from simple formulas based on layer thicknesses but requires the simulation of the propagation depth of ISWs in continuous stratification. The propagation depth of ISWs in continuous stratification can be derived by solving the DJL equation or approximated by solving formula (3).

[47] The absolute values of the instability thresholds in terms of $n l_{p}$ are close to the thresholds derived for $n l$ in the laboratory by Grue et al. [2000]. Owing to the good agreement of the stability thresholds, a transfer of the threshold for weakly nonlinear ISWs obtained in the laboratory to field conditions seems reasonable. Applying a boundary value of $n l_{p}=0.4$, as was suggested by Grue et al. [1999] for $n l$ in a two-layer stratification, characterizes $60 \%$ of the observed ISWs as strongly nonlinear. Thus their simulation requires models that can account for nonlinear waves. However, the threshold of $n l_{p}=0.4$ seems rather generous because the vertical structure of ISWs simulated with the DJL model for stratifications that typically support ISWs with $n l_{p} \approx 0.4$ differs from the vertical structure of ISWs obtained with the $\mathrm{KDV}$ for the same stratifications. This implies that even at $n l_{p}=0.4$ the ISWs are nonlinear and suggests that the percentage of strongly nonlinear ISWs in Lake Constance might be larger than $60 \%$. Modeling approaches based on weakly nonlinear theory may be insufficient to describe ISWs in Lake Constance and may also not be applicable in other lakes, in which large ISWs have already been observed.

[48] The connection between season and measured ISW properties was supported by the simulation of seasonal ISW prototypes. Observed significant trends of ISW properties such as the increase of propagation depth over the year and the enhanced degree of nonlinearity in spring were predicted by both models. This suggests that the observed seasonal variation of ISW propagation depth and degree of nonlinearity is caused by seasonally varying stratification. The large percentage of strongly nonlinear waves in spring coincides with the observation of an extremely high proportion of waves accompanied by density inversions in May. Since unstable ISWs especially occur in May around the annual peak in phytoplankton when nutrients have been depleted, mixing associated with ISWs possibly provides nutrients to the nutrient-depleted euphotic zone and may thus play a special role in early summer plankton dynamics [Anneville et al., 2005; Peeters et al., 2007].
[49] ISWs have been observed in numerous other lakes, such as Loch Ness [Thorpe et al., 1972], Lake Babine [Farmer, 1978], Seneca Lake [Hunkins and Fliegel, 1973], and Lake Biwa [Saggio and Imberger, 1998], where ISWs are associated with a steepened basin-scale seiche [Horn et al., 2001]. They also occur in fjord-like systems [Bourgault et al., 2011] and in the ocean. The seasonal dependence of the degree of nonlinearity of ISWs, and therefore a possible change in the ecological influence of ISWs over the year, can be expected in any aquatic systems whose stratification varies with season. According to our results, nonlinear effects should be favored during the onset of stratification, when the thermocline depth is low, as was speculated by Farmer [1978] based on a two-layer model for Lake Babine. Strongly nonlinear phenomena such as waves with trapped cores occur only if the ISW degree of nonlinearity is very large. Observations of such highly nonlinear waves have been presented from Lake Biwa, where ISWs with $n l_{p} \approx 1$ occurred after a typhoon [Saggio and Imberger, 1998].

[50] The formation of a trapped core and the occurrence of shear instabilities are not necessarily an effect of shoaling, as numerical investigations indicate [Barad and Fringer, 2010; Lamb and Farmer, 2011; Stastna and Lamb, 2002]. In the deep ocean, observations of ISWs accompanied by turbulence are not uncommon, and the turbulence is usually assumed to be generated by shear instabilities [e.g., Orr and Mignerey, 2003]. Observations of ISWs with shear instabilities were, for example, presented by Moum et al. [2003] for the Oregon Shelf, where instabilities occurred at similar depth and wave amplitude as shown in our study. The stratification in the work of Moum et al. [2003] was significantly stronger but had a shape roughly similar to the autumn stratification in Lake Constance. Our observations demonstrate that the occurrence of strongly nonlinear waves and wave-breaking in deep water is not restricted to ocean conditions, but is a regular occurrence in Lake Constance and may also be a common phenomenon in other lakes. In contrast to most oceanic conditions, in deep temperate lakes the stratification extends up to the surface, and Lake Constance is an example of this. This type of stratification supports waves of depression with trapped cores [Lamb, 2002], which therefore might be more frequent in lakes than in the ocean.

[51] Acknowledgments. This work was only possible due to the indefatigable commitment of the technicians B. Rosenberg and J. Halder to maintain the long-term temperature chain. The radio link to the data buoy was made possible by O. Kotheimer and the School Salem Castle. We thank M. Stastna and M. Carr for illuminating discussions during the 2nd Norway-Scotland internal waves symposium and P. Davies for his invitation to that most inspiring conference. We are grateful to M. Stastna and C. Subich for generously providing us with their code for solving the DJL equation. We also want to thank two anonymous reviewers for very helpful suggestions. This work was supported by the German research association (DFG, PE 701/4-1).

\section{References}

Aghsaee, P., L. Boegman, and K. G. Lamb (2010), Breaking of shoaling internal solitary waves, J. Fluid Mech., 659, 289-417, doi:10.1017 S002211201000248X.

Anneville, O., S. Gammeter, and D. Straile (2005), Phosphorus decrease and climate variability: Mediators of synchrony in phytoplankton changes among European peri-alpine lakes, Freshwater Biol., 50(10), 1731-1746, doi:10.1111/j.1365-2427.2005.01429.x. 
Appt, J., J. Imberger, and H. Kobus (2004), Basin-scale motion in stratified upper Lake Constance, Limnol. Oceanogr., 49(4), 919-933, doi:10.4319/ 10.2004.49.4.0919.

Barad, M. F., and O. B. Fringer (2010), Simulations of shear instabilities in interfacial gravity waves, J. Fluid Mech., 644, 61-95, doi:10.1017/ S0022112009992035.

Bäuerle, E., D. Ollinger, and J. Imberger (1998), Some meteorological, hydrological, and hydrodynamical aspects of Upper Lake Constance, Arch. Hydrobiol. Spec. Issues Adv. Limnol., 53, 31-83.

Benjamin, T. B. (1967), Internal waves of permanent form in fluids of great depth, J. Fluid Mech., 29(3), 559-592, doi:10.1017/S002211206700103X.

Benney, D. J. (1966), Long nonlinear waves in fluid flows, J. Math Phys. Cambridge Mass., 45(1), 52-63.

Benney, D. J., and D. R. S. Ko (1978), Propagation of long large-amplitude internal waves, Stud. Appl. Math., 59(3), 187-199.

Boegman, L., and G. N. Ivey (2009), Flow separation and resuspension beneath shoaling nonlinear internal waves, J. Geophys. Res., 114, C02018, doi:10.1029/2007JC004411.

Boegman, L., G. N. Ivey, and J. Imberger (2005), The energetics of largescale internal wave degeneration in lakes, J. Fluid Mech., 531, 159-180, doi:10.1017/S0022112005003915.

Bogucki, D., and C. Garrett (1993), A simple model for the shear-induced decay of an internal solitary wave, J. Phys. Oceanogr., 23(8), 1767-1776, doi:10.1175/1520-0485(1993)023<1767:ASMFTS >2.0.CO;2.

Bonnin, J., H. Van Haren, P. Hosegood, and G. J. A. Brummer (2006), Burst resuspension of seabed material at the foot of the continental slope in the Rockall Channel, Mar. Geol., 226(3-4), 167-184, doi:10.1016/j. margeo.2005.11.006.

Bourgault, D., D. C. Janes, and P. S. Galbraith (2011), Observations of a large-amplitude internal wave train and its reflection off a steep slope, J. Phys. Oceanogr., 41(3), 586-600, doi:10.1175/2010JPO4464.1.

Carr, M., D. Fructus, J. Grue, A. Jensen, and P. A. Davies (2008), Convectively induced shear instability in large amplitude internal solitary waves, Phys. Fluids, 20(12), 126601, doi:10.1063/1.3030947.

Carr, M., M. Stastna, and P. A. Davies (2010), Internal solitary waveinduced flow over a corrugated bed, Ocean Dyn., 60(4), 1007-1025, doi:10.1007/s10236-010-0286-2.

Chen, C. T. A., and F. J. Millero (1986), Precise thermodynamic properties for natural waters covering only the limnological range, Limnol. Oceanogr., 31(3), 657-662, doi:10.4319/lo.1986.31.3.0657.

Cuypers, Y., B. Vincon-Leite, A. Groleau, B. Tassin, and J. F. Humbert (2011), Impact of internal waves on the spatial distribution of Planktothrix rubescens (cyanobacteria) in an alpine lake, ISME J., 5(4), 580-589, doi:10.1038/ismej.2010.154.

de la Fuente, A., K. Shimizu, Y. Nino, and J. Imberger (2010), Nonlinear and weakly nonhydrostatic inviscid evolution of internal gravitational basin-scale waves in a large, deep lake: Lake Constance, J. Geophys. Res., 115, C12045, doi:10.1029/2009JC005839.

Dubreil-Jacotin, M. L. (1935), Complément à une note antérieure sur les ondes de type permanent dans les liquides hétérogènes, Atti R. Acc. Naz. Lincei, 21(6), 344-346.

Farmer, D. M. (1978), Observations of long non-linear internal waves in a lake, J. Phys. Oceanogr., 8(1), 63-73, doi:10.1175/1520-0485(1978) 008<0063:OOLNIW $>2.0$.CO;2

Farmer, D. M., et al. (2011), From Luzon Strait to Dongsha Plateau: Stages in the life of an internal wave, Oceanography, 24(4), 64-77, doi:10.5670/ oceanog.2011.95.

Fructus, D., M. Carr, J. Grue, A. Jensen, and P. A. Davies (2009), Shearinduced breaking of large internal solitary waves, J. Fluid Mech., 620, 1-29, doi:10.1017/S0022112008004898.

Goudsmit, G. H., F. Peeters, M. Gloor, and A. Wuest (1997), Boundary versus internal diapycnal mixing in stratified natural waters, J. Geophys. Res., 102(C13), 27,903-27,914, doi:10.1029/97JC01861.

Grue, J., A. Jensen, P. O. Rusas, and J. K. Sveen (1999), Properties of large-amplitude internal waves, J. Fluid Mech., 380, 257-278, doi:10.1017/S0022112098003528.

Grue, J., A. Jensen, P. O. Rusas, and J. K. Sveen (2000), Breaking and broadening of internal solitary waves, J. Fluid Mech., 413, 181-217, doi:10.1017/S0022112000008648.

Helfrich, K. R., and W. K. Melville (2006), Long nonlinear internal waves, Annu. Rev. Fluid Mech., 38, 395-425, doi:10.1146/annurev.fluid.38. 050304.092129.

Helfrich, K. R., and B. L. White (2010), A model for large-amplitude internal solitary waves with trapped cores, Nonlinear Proc. Geophys., 17(4), 303-318, doi:10.5194/npg-17-303-2010.

Horn, D. A., J. Imberger, and G. N. Ivey (2001), The degeneration of largescale interfacial gravity waves in lakes, J. Fluid Mech., 434, 181-207, doi:10.1017/S0022112001003536.
Huber, A. M. R., F. Peeters, and A. Lorke (2011), Active and passive vertical motion of zooplankton in a lake, Limnol. Oceanogr., 56(2), 695-706, doi:10.4319/lo.2011.56.2.0695.

Hunkins, K., and M. Fliegel (1973), Internal undular surges in Seneca Lake: A natural occurrence of solitons, J. Geophys. Res., 78(3), 539-548, doi:10.1029/JC078i003p00539.

Jackson, C. (2007), Internal wave detection using the Moderate Resolution Imaging Spectroradiometer (MODIS), J. Geophys. Res., 112, C11012, doi:10.1029/2007JC004220.

James, G. (1997), Small amplitude steady internal waves in stratified fluids, Ann. Univ. Ferrara, 43(1), 65-119, doi: 10.1007/bf02837229.

Klymak, J. M., and J. N. Moum (2003), Internal solitary waves of elevation advancing on a shoaling shelf, Geophys. Res. Lett., 30(20), 2045, doi:10.1029/2003GL017706.

Lamb, K. G. (2002), A numerical investigation of solitary internal waves with trapped cores formed via shoaling, J. Fluid Mech., 451, 109-144, doi:10.1017/S002211200100636X.

Lamb, K. G., and D. Farmer (2011), Instabilities in an internal solitarylike wave on the Oregon Shelf, J. Phys. Oceanogr., 41(1), 67-87, doi:10.1175/2010JPO4308.1.

Lamb, K. G., and V. T. Nguyen (2009), Calculating energy flux in internal solitary waves with an application to reflectance, J. Phys. Oceanogr., 39(3), 559-580, doi:10.1175/2008JPO3882.1.

Ledwell, J. R., A. J. Watson, and C. S. Law (1993), Evidence for slow mixing across the pycnocline from an open-ocean tracer-release experiment, Nature, 364(6439), 701-703, doi:10.1038/364701a0.

Long, R. R. (1956), Solitary waves in the one-fluid and 2-fluid systems, Tellus, 8(4), 460-471, doi:10.1111/j.2153-3490.1956.tb01249.x.

Lorke, A. (2007), Boundary mixing in the thermocline of a large lake, J. Geophys. Res., 112, C09019, doi:10.1029/2006JC004008.

Lorke, A., F. Peeters, and E. Bauerle (2006), High-frequency internal waves in the littoral zone of a large lake, Limnol. Oceanogr., 51(4), 1935-1939, doi:10.4319/lo.2006.51.4.1935.

MacIntyre, S., J. F. Clark, R. Jellison, and J. P. Fram (2009), Turbulent mixing induced by nonlinear internal waves in Mono Lake, California, Limnol. Oceanogr., 54(6), 2255-2272, doi:10.4319/lo.2009.54.6.2255.

Mackas, D. L., K. L. Denman, and M. R. Abbott (1985), Plankton patchiness: Biology in the physical vernacular, Bull. Mar. Sci., 37(2), 652-674.

Miles, J. W. (1980), Solitary waves, Annu. Rev. Fluid Mech., 12, 11-43, doi:10.1146/annurev.fl.12.010180.000303.

Moum, J. N., D. M. Farmer, W. D. Smyth, L. Armi, and S. Vagle (2003), Structure and generation of turbulence at interfaces strained by internal solitary waves propagating shoreward over the continental shelf, J. Phys. Oceanogr., 33(10), 2093-2112, doi:10.1175/1520-0485(2003)033<2093: SAGOTA $>2.0 . \mathrm{CO} ; 2$.

Moum, J. N., D. M. Farmer, E. L. Shroyer, W. D. Smyth, and L. Armi (2007), Dissipative losses in nonlinear internal waves propagating across the continental shelf, J. Phys. Oceanogr., 37(7), 1989-1995, doi:10.1175/ JPO3091.1.

Orr, M. H., and P. C. Mignerey (2003), Nonlinear internal waves in the South China Sea: Observation of the conversion of depression internal waves to elevation internal waves, J. Geophys. Res., 108(C3), 3064, doi:10.1029/2001JC001163.

Ostrovsky, L. A., and Y. A. Stepanyants (2005), Internal solitons in laboratory experiments: Comparison with theoretical models, Chaos, 15(3), 037111, doi:10.1063/1.2107087.

Peeters, F., D. Straile, A. Lorke, and D. M. Livingstone (2007), Earlier onset of the spring phytoplankton bloom in lakes of the temperate zone in a warmer climate, Global Change Biol., 13(9), 1898-1909, doi:10.1111/j.1365-2486.2007.01412.x.

Pineda, J. (1999), Circulation and larval distribution in internal tidal bore warm fronts, Limnol. Oceanogr., 44(6), 1400-1414, doi:10.4319/ 1o.1999.44.6.1400.

Preusse, M., F. Peeters, and A. Lorke (2010), Internal waves and the generation of turbulence in the thermocline of a large lake, Limnol. Oceanogr., 55(6), 2353-2365, doi:10.4319/lo.2010.55.6.2353.

Saggio, A., and J. Imberger (1998), Internal wave weather in a stratified lake, Limnol. Oceanogr., 43(8), 1780-1795.

Stastna, M., and K. G. Lamb (2002), Large fully nonlinear internal solitary waves: The effect of background current, Phys. Fluids, 14(9), 2987-2999, doi:10.1063/1.1496510.

Stastna, M., and K. G. Lamb (2008), Sediment resuspension mechanisms associated with internal waves in coastal waters, J. Geophys. Res., 113, C10016, doi:10.1029/2007JC004711.

Thorpe, S. A., I. Crofts, and A. Hall (1972), The internal surge in Loch Ness, Nature, 237(5350), 96-98, doi:10.1038/237096b0.

Turkington, B., A. Eydeland, and S. Wang (1991), A computational method for solitary internal waves in a continuously stratified fluid, Stud. Appl. Math., 85(2), 93-127. 
Vlasenko, V., P. Brandt, and A. Rubino (2000), Structure of largeamplitude internal solitary waves, J. Phys. Oceanogr., 30(9), 2172-2185, doi:10.1175/1520-0485(2000)030<2172:SOLAIS > 2.0.CO;2.

Wessels, M. (1998), Geological history of the Lake Constance area, Arch. Hydrobiol. Spec. Issues Adv. Limnol., 53, 1-12.

Zenger, A., W. Anker, J. Ilmberger, and K. O. Münnich (1990), Die Untersuchung der Windverhältnisse im westlichen Teil des Bodensees und die Umrechung von Landwinden auf Seebedingungen, Meteorol. Rundsch., 42, 42-51.

Zheng, Q., R. D. Susanto, C. R. Ho, Y. T. Song, and Q. Xu (2007), Statistical and dynamical analyses of generation mechanisms of solitary internal waves in the northern South China Sea, J. Geophys. Res., 112, C03021, doi:10.1029/2006JC003551.

H. Freistühler, Department of Mathematics and Statistics, University of Konstanz, Universitätsstraße 10, D-78457 Konstanz, Germany. (heinrich. freistuehler@uni-konstanz.de)

F. Peeters and M. Preusse, Limnological Institute, University of Konstanz, Mainaustr. 252, D-78464 Konstanz, Germany. (frank.peeters@ uni-konstanz.de; martina.preusse@uni-konstanz.de) 